\title{
Mental Health of Actors (male and female) in the Film Industry - A Study of its Causes, Effects, and Recommendations
}

\author{
Preeti Vaswani \\ Assistant Professor, Department of English, L.S. Raheja College of Arts and Commerce, Mumbai. \\ Corresponding author: Dr. Preeti Vaswani
}

\begin{abstract}
Many actors face anxiety and depression, but do not speak about it. They are ashamed of their emotions, of projecting a poor self-image, and end up doing greater harm to themselves. However, perspectives on mental health are changing and successful actors are publically discussing their anxiety issues and depression. This article explores the same further.

The stigma around mental health is slowly and steadily loosening from the shackles. Celebrities speaking about and starting the conversation around mental health can bring a positive reinforcement to bring down stigma around mental health.
\end{abstract}

Keywords: Mental Health, Film Industry, Female Actors, Male Actors.

(Paper received $-4^{\text {th }}$ January 2018 , Peer review completed $-7^{\text {th }}$ January 2018)

(Accepted $-9^{\text {th }}$ January 2018)

According to Merriam-Webster's Dictionary, mental health is the condition of being sound mentally and emotionally that is characterized by the absence of mental illness and by adequate adjustment especially as reflected in feeling comfortable about oneself, positive feelings about others, and the ability to meet the demands of daily life [1]. Generally speaking, all stress is not bad. A small dose of stress is good, as it can help one meet daily challenges, provides motivation to reach one's goals, provides learning experience to perform more efficiently, and makes one physically and mentally strong. But when stress levels go high, it can turn to be detrimental to a person's well-being. Family stress and work stress are general everyday challenges of most people in the world. Being in a particular profession can also add to one's stress and affect one's mental health. Acting is one such profession. Getting into the industry is not an easy task; making a living out of it is a greater challenge. Fame, popularity, glamour, richness, a lavish lifestyle, attention and admiration are some of the gleaming highlights that the film industry seems to offer, attracting more and more youngsters day by day, as moths to light. Most new comers inevitably face rejection again and again, and by the time they get used to the idea of rejection, they lose much of their confidence, enthusiasm, and optimism, and are left with a poor self-image. On the other hand, after a little success, they generally become too choosy about their roles, and end up without any work in hand. Even those who are well placed in the industry fear decline and competition, because, even a couple of unsuccessful films in a row pulls down their success graph and affects their future work. The paper attempts to explore the dark and unstable world of film actors, and the factors that contribute to mental disorders or psychological disturbances in them as a result of being in the profession.

Many actors face anxiety and depression, but do not speak about it. They are ashamed of their emotions, of projecting a poor self-image, and end up doing greater harm to themselves. However, perspectives on 
mental health are changing and successful actors are publicly discussing their anxiety issues and depression.

Singer and actor Yo Yo Honey Singh reveals having suffered from bipolar disorder. The singer/composer who had performed before huge crowds of over twenty thousand people was scared of facing even four to five people as a result of this condition. Deepika Padukone is another actor who has openly spoken about her depression. Anushka Sharma too tweeted on her anxiety issues, and emphasised the need for people to be vocal about their psychological problems, if any. Sometimes, playing a particular character in a film causes depression in the actor (as in the case of Varun Dhawan in Badlapur). The involvement required in playing an intense character with conviction lingers on, and the hangover has a huge effect on the actor. Talking about the effect Highway had on Randeep Hooda, he confesses, "After Highway, I was depressed for a long time. I had to tell myself that I am not a petty taxi driver, and that is not my life [2]." Even Aamir Khan had to go under medication for his post-traumatic disorder while shooting for his show Satyamev Jayate. He stated that "Unwrapping hidden painful truths of society was not an easy task and meeting such people who have been through a dreadful phase of life was heart-wrenching [3]." The experience of actors in horror films too, can turn out to be traumatic. Some of them are known to have suffered hallucinations, even while shooting for the movie and afterward. Playing a passionate character too, can be a great challenge. Intimate scenes, nudity, rumours of link-ups with co-actors lead to rough or broken marriages, and can add to their trauma. Those who are launched in the industry by their parents or relatives also face a lot of pressure, as they are judged against the stardom of their godfathers.

Competition and jealousy go hand in hand, and are the key emotions in film politics. The sense of satisfaction of one's success is short-lived, because equations and positions in the industry keep changing by the day. One's success is not directly related to one's achievements, but is at the same time inversely proportional to another's failure. The space at the top is too narrow to hold anyone in balance for long. Even those who have remained in the industry for decades, as in the cases of Amitabh Bachchan, Salman Khan, Shah Rukh Khan, etc., have faced periods of downfall and trauma. Undergoing unnecessary plastic surgeries to craft a body to aesthetic perfection is one of the reactions to Body Dysmorphic Disorder (BDD) that some actors, especially women, suffer from. In an attempt to correct perceived imperfections, they end up going too many times under the knife. According to the Anxiety and Depression Association of America,

They can't control their negative thoughts and don't believe people who tell them that they look fine. Their thoughts may cause severe emotional distress and interfere with their daily functioning. They may miss work or school, avoid social situations and isolate themselves, even from family and friends, because they fear others will notice their flaws [4].

Bollywood Diaries (2016) is an enlightening and unnerving film about three unrelated individuals from different fields and backgrounds who aspire to make a career in Bollywood - the Hindi film industry. The award winning and critically acclaimed film is a tribute to the struggling aspirants of Bollywood. Fifty-two year old Vishnu (played by Ashish Vidyarthi) who is in the final stage of pancreatic cancer, and who is obsessed with Bollywood beyond unimaginable limits, goes to the extent of convincing his wife to get him a renowned pandit who, by performing special pujas, would pave the way for him to be reborn in the home of a Bollywood superstar, and become an actor in his next birth. Twenty-seven year old Rohit from Delhi (played by Salim Diwan) faces unfruitful auditions, is emotionally shattered, psychologically disturbed, becomes violent and abnormal, and ends up becoming a social deviant. Imli, a sex-worker from Kolkata (played by Raima Sen) is heart-broken on being duped by an assistant film director who manipulates her with the promise of casting her in his next film. She settles at becoming a dancer in a posh night club in Dubai.

Films such as The Dirty Picture, Who Lamhe, Heroine, etc. depict the rise and fall of women actors, and the effect it has on their psyche. Where Mahi Arora of Heroine quits the industry, and abandons her identity as an actor, Silk in The Dirty Picture quits the world. And, in both cases, the response is due to the depression of a declining career, of coming face to face with inauthenticity and hypocrisy, and the realisation of the emptiness and void in their life. They end up committing mistakes in a fit of desperation 
and frustration, lose their self-respect, and decide to move on or move out. Actor Parveen Babi of yesteryears is known to have suffered from acute schizophrenia and to have committed suicide. A fictionalised version of her life is presented in Who Lamhe, where she is shown to be seemingly successful and independent, but actually craves for love, understanding, and realisation of meaning in her life.

Success and inner happiness are not mutual. Fame brings with it the fear of being judged. In a National Survey conducted by Equity in 2013 on the well-being of actors, Dr. Mark Seton of the University of Sydney worked on identifying the factors that cause real distress to actors. His findings reveal that there were important areas in the training of actors that clearly had implications on the actors for their long-term sustainable working practice and lifestyle. He finds that, surprisingly, actors were not stressed when in the job, but when waiting for the next job. During this period of wait, they experienced low self-esteem and a sense of rejection. The uncertainty of the profession contributed very highly to their increased levels of anxiety followed by depression. Moreover, the profession being highly demanding both psychologically and physically, the actors feel isolated because they feel no one understands this challenging career. They find it difficult to manage significant relationships - family, friends, one significant partner, and therefore have high levels of anxiety and depression more than the general population. This leads to a higher abuse of alcohol particularly, and a lesser abuse of drugs.

Dr. Seton goes on to add that what begins as occasional social drinking, becomes habitual, and then converts to excessive drinking even when alone. He points out that where actors were trained in general diet and healthy practices, they were given no training in financial management and working on significant relationships in their life. He also emphasizes on the need for a supporting career to fall back on, as they face lean periods and rich periods, and are not always in the job, but in-between jobs. Psychologically, actors need to understand that they are human beings first, and actors second. They need to be self-caring, self-forgiving on one's mistakes, and to be able to connect with other people in a trustful way during times of lows. They need to be resilient, as they are more vulnerable to being judged and trolled. They need to be proactive about financial management, and also need to be able to accept the highs and lows of their profession. However, there is also a need for a supportive network, due to the fluctuating nature of the profession, and also because there is a feeling of rejection till the actor reaches the next level. These are skills that are learnable, to make more sustainable actors, who are resilient risk-takers [5].

In my interview with actor Sonali Kulkarni in December 2017, she reasons that all humans are performers in their life, the only difference being that actors exercise a variety of emotions falsely, while playing a given character. She adds that acting is as normal as any other profession, and there is nothing extraordinary about it. The uniqueness of it comes from the fact that actors are exposed to fame and publicity, which actually comes with a price. Paradoxically, there is a desire for popularity that unfortunately comes with an intrusion to privacy. This publicity stress is one of the factors that causes anxiety to some or most actors. Another factor is that actors, though temporarily, live the character they are playing in a film. Recalling her role in Dr. Babasaheb Ambedkar (2000) she says, "I was getting choked everyday playing Ambedkar's wife in a film. There are moments when you feel too much for the character." This is a challenging discrimination that an actor needs to realize - the need to empathise with the character rather than live the character; to go through this parallel journey with a sense of detachment from true emotions.

Needless rumours and gossip being another factor that can cause turbulence in an actor's life, Mrs. Kulkarni emphasizes on the need for emotional and psychological maturity to detach oneself from gossip. She adds that handling relationships also turns out to be a challenging task. Also, there is sometimes the guilt factor of not being able to make oneself available or connect dearly to one's family or loved ones. The longing to be with one's circle amidst an exhausting schedule also takes a toll on the mind. She discusses that actors generally lead a hectic lifestyle with no routine, no holidays, and no regular sleep. They are generally under-rested, and exhausted both physically and mentally. By living life in this way for a few years, they extract the entire enthusiasm and tenacity from within themselves, and begin to yearn for a more stable and balanced state of being. Women actors, generally, choose to achieve this by getting married, nurturing relationships, having children, thereby taking a break from their career. After having enjoyed the serenity of a private life and complacency in relationships they gradually get to realise that 
what is missing in their life is the limelight they once enjoyed. Getting back one's position in the industry after a break is generally not easy, for which the industry cannot be blamed. One therefore needs to be clear about one's own choices, and not portray oneself as a victim. Mrs. Kulkarni insists on the need for a fall-back profession such as writing, starting an acting school to groom fresh aspirants, working as a dubbing artist, starting a new business such as fashion designing, home décor, or anything else of one's interest. She appreciates actors like Dimple Kapadia - with whom she worked in DilChahta Hai - who has worked in various phases of her life, and has remained successful through hard work. Married as well as professionally successful, Kulkarni hails being in the profession, which she calls a fantastic scholarship. What one needs to learn, she adds, is to keep jealousy and insecurity at bay, to be empathetic to oneself, to work on one's reactions, to remain grounded, and not let stardom weigh on the mind. She concludes that one ultimately needs to discover oneself as an actor without losing touch with the real self.

\title{
REFERENCES
}

1. Mental Health. Merriam-Webster [Internet]. Accessed from:Dec 252017.

2. Phillips KA. Body dysmorphic disorder: the distress of imagined ugliness. Am J Psychiatry. 1991 Sep 1;148(9):1138-49.

3. 10 Bollywood Superstars Who Fought Mental Illness And Spoke About It Publicly. [Dec 25, 2017]. Accessed: https://www.naukrinama.com/stressbuster/10-bollywood-celebrities-who-suffered-depressionand-anxiety/

4. Seton M. 'Post-Dramatic'Stress: Negotiating Vulnerability for Performance. 